\title{
Why occupational therapy?
}

\author{
A. JAWAd Sheikh, Consultant Psychiatrist, Hollymoor Hospital, \\ Birmingham B31 5EX; and DeBbIE BoultaN, Senior Occupational Therapist, \\ Midland Nerve Hospital, Birmingham, B15 2NJ
}

Occupational therapy as a discipline (Finlay, 1988) has grown and matured with time. It has moved away from an ill-defined, imprecise and informal discipline to one which, while treating the patient as a whole being, nevertheless attempts to identify an individual's unique problems and treats them through purposeful activity. It strives to attain the qualities of a holistic, goal-orientated objective process.

Occupational therapy may be defined as the treatment of physical and psychiatric conditions through specific activities to help people reach their maximum level of function and independence in daily life. Occupational therapy assesses and treats people using purposeful activity to prevent disability and develop independent function.

\section{Aims of the study}

The study aimed to evaluate the attitudes and views of doctors, nurses and patients towards occupational therapy. By studying their opinions and views we hoped to determine:

(a) the level of their knowledge and understanding of occupational therapy as a therapeutic tool and

(b) to have some idea about the importance of occupational therapy in this particular clinical setting.

\section{Setting}

The study was undertaken at Midland Nerve Hospital. It is a psychiatric teaching hospital annexe with an academic attachment. It consists of two acute admission wards, a three-bedded high dependency unit, and a day hospital which was excluded from the study. There are five consultants based within the hospital each with a team of two junior doctors. Most of the consultants work in a multidisciplinary setting, where the referrals to occupational therapy are also discussed.

\section{The study}

The survey was completed over ten months. During the period there was one rotational change of junior medical staff, so 20 doctors contributed to the project; 6 senior house officers, 6 registrars, 3 senior registrars and 5 consultants. The following questionnaires were specifically designed for the study.

\section{Staff questionnaires (doctors and nurses)}

This enabled us to evaluate doctors' and nurses' knowledge and views about occupational therapy. It also gave us some idea about the level of importance the doctors and nurses assigned to occupational therapy. They had to give reasons for their referral.

The nurses' questionnaire was completed by a qualified nurse who was also familiar with the patient.

\section{Patients' questionnaire - Part I}

Patients were asked to complete this questionnaire after a doctor had referred them to occupational therapy but before the occupational therapist had seen them for an initial interview. The questionnaire consisted of Yes/No answers to six specific questions, geared to evaluate whether the doctors and nursing staff did explain the reasons behind the referral to occupational therapy. It aimed to evaluate the willingness to attend occupational therapy and to determine the existing level of knowledge as to being treated by an occupational therapist.

\section{Patients' questionnaire - Part II}

This was completed on discharge from the hospital. It was designed to enable us to monitor significant change in attitudes towards OT after treatment, and to detail the types of treatment received; 11 of the 14 questions could be answered simply Yes and No. The remaining three questions asked patients' views about the general environment of the occupational therapy department, the quality of relationship with the staff, and the type of treatment received.

\section{Subjects}

We received 60 doctors' questionnaires, a rather poor 25 nursing questionnaires in spite of numerous requests, 48 patients filled in Part I questionnaires, and 35 filled in Part II patient questionnaires. 


\section{Findings}

Doctors' responses

Out of 60 doctors' referrals, 3 were filled in by a consultant, 31 by registrars and 26 by senior house officers. The analysis of the "objective" of their referral was a much more tedious task. The demand for "improving skills" was high with requests for "fuller assessment", "improve ability to concentrate" and to "occupy time and mind" in that order. There were two requests for domestic assessments and two referral forms had no objective written. Of the doctors, $83 \%$ regarded occupational therapy as very important or important for their patients; $66 \%$ felt occupational therapy helped to clarify the diagnosis, improved the coping skills of the depressed patients, and helped the patient to improve his or her skills and functioning; $28 \%$ of the doctors gave no reason for selecting occupational therapy for their patients. The rest gave reasons like "needs quick intervention to stop self-harm" or "patient might lose his job". Forty-one per cent believed that OT helped to improve social skills of the patient and contributed to fuller assessment of the patients' psychiatric condition; $18 \%$ wrote that it gave something for the patient to occupy his time and mind; $31 \%$ did not answer the questions. The rest mentioned "improving self-esteem", "improving motivation" and helping "overcome boredom on the wards".

\section{Nursing responses}

Efforts were made for the forms to be completed by the key worker but it was not always possible. The results from the nursing questionnaire were similar to the doctors' views. When asked to write reasons for the importance of occupational therapy or the way OT contributed to psychiatric well-being, $24 \%$ of the forms were blank.

\section{Patients' responses (Part I)}

Of the 48 patients, $59 \%$ were not informed of the occupational therapy referral; $46 \%$ of the patients were not consulted by their doctor or nurse before being referred and $61 \%$ were not aware that occupational therapy was part of their treatment. Nonetheless $91 \%$ were happy to attend OT but only $55 \%$ felt it was relevant to their illness.

\section{Patients' responses (Part II)}

Of the 35 patients, $97 \%$ found occupational therapy beneficial and $88 \%$ felt it helped their illness, $77 \%$ of the patients were given the choices in the occupational treatment ( $23 \%$ were not), and $91 \%$ were satisfied with the explanation given about occu- pational therapy. Of the patients, $64 \%$ did not feel that it was disruptive when called out of occupational therapy when needed elsewhere, for example to see a doctor. Preference for individual or group work was equal and $73 \%$ were satisfied with the time allocated to occupational therapy. Fifty-eight per cent felt the treatment environment in occupational therapy was not adult-like although $94 \%$ of the patients denied it was patronising. Sixty-eight per cent of the patients felt the treatment environment was one of mutual respect ( $32 \%$ did not). Ninety-seven per cent felt that OT was a useful part of their treatment and about the same number were pleased to attend.

\section{Conclusion}

We were not surprised by the overall outcome of the study. The prediction of referring agents' vagueness of purpose when considering occupational therapy was borne out by the results. The doctors were unclear about occupational therapy as a tool and, although they regarded it as an important aspect of treatment, found it difficult to give clear-cut reasons for referral. The low response from nurses was surprising as we felt that nurses would be more enthusiastic and knowledgeable about referring. This could be a reflection of being too busy or lack of interest. A quarter of their forms were left blank when asked to give a reason or explanation for their referral, reflecting lack of understanding of the role of occupational therapy.

It was worrying that doctors and nurses still refer patients without prior consultation. Nearly $60 \%$ were not told before referral and nearly $63 \%$ not consulted about the reasons for being sent to occupational therapy. This illustrates lack of involvement of the patient in a treatment programme and an apparent disinclination by the professionals to consult patients about their treatment and referrals.

Part II of the patients' questionnaire was encouraging and positive about occupational therapy. The consumer satisfaction was high and realistic. The treatment environment remains crucial in occupational therapy. It has long tended to be excessively "parental" and at times even patronising. Although a very high proportion of clients did not regard the treatment environment as patronising a majority $(60 \%)$ felt it was not adult-like. This needs to be taken seriously if we are to involve patients in a treatment programme which respects individuality and informed choice.

This study confirmed the importance, value and the therapeutic role of modern occupational therapy in the care of psychiatric patients, both from the professionals' and patients' point of view, but the selection of patients' choice of goals and involvement of the patients themselves in the process was far from 
ideal. A larger study including other centres would help to test these impressions and assess alternative approaches.

\section{Acknowledgement}

We would like to thank Dr Fiona Macmillan, Senior Lecturer, University of Birmingham and Dr Martin Davies, Consultant Psychiatrist, Midland Nerve Hospital for their very helpful and relevant comments on the paper.

\section{Reference}

Finlay, L. (1988) Occupational Therapy: Practice in Psychiatry, London: Croom Helm.

\section{Further reading}

BALlinger, B. R. (1971) The patients' view of psychiatric treatment. Health Bulletin, 29, 192-196.

CoIA, D. \& JoICE, A. (1989) Occupational therapy - the forgotten speciality with the community mental health team? Psychiatric Bulletin, 13, 420-421.

\title{
Audit in practice
}

\section{Short duration induced seizures and therapeutic outcome at electroconvulsive therapy applications}

\author{
J. P. Joyce, Locum Associate Specialist, Ogwr Health Unit, Glanrhyd \& Penyfair \\ Hospitals, Bridgend, Mid Glamorgan CF31 4LN
}

Electroconvulsive therapy (ECT) is reported the most effective treatment for severe endogenous depressive illness but may also be useful in the treatment of mania and schizophrenia. It seems that the seizure is a necessary component of the overall treatment but it is undecided what constitutes an adequate duration of seizure activity.

The Royal College of Psychiatrists (1989) recommend that seizures of 25 seconds or more should be aimed for and that restimulation at a given session should be carried out if a seizure of 15 seconds or less occurs. Restimulation at a given session should also be carried out if there is no observable seizure, or if there is a unilateral or focal seizure.
I decided to examine all applications of ECT to patients in the local psychiatric hospital to ascertain what proportion of the total have seizures of duration less than 15 seconds and to assess the reasons for these patients to have short duration fits. I also looked at the therapeutic outcome for this group of patients.

\section{The study}

A list of all patients given ECT is available in the ECT Department. I examined the ECT records as well as medical case-notes of all patients who had received ECT between 1 January and 30 June 1990. 